\title{
28 Research Square \\ Exposure effects of the UV-filter 4-MBC to "Solea senegalensis" metamorphosis
}

\section{Mário Araújo ( $\nabla$ mjaraujo@ua.pt )}

CESAM: Universidade de Aveiro Centro de Estudos do Ambiente e do Mar https://orcid.org/0000-00032552-6853

\section{Amadeu Soares}

CESAM: Universidade de Aveiro Centro de Estudos do Ambiente e do Mar

\section{Marta Monteiro}

CESAM: Universidade de Aveiro Centro de Estudos do Ambiente e do Mar

\section{Research Article}

Keywords: biochemical markers, early development, flatfish, marine vertebrates, oxidative stress, personal care products

Posted Date: February 23rd, 2021

DOl: https://doi.org/10.21203/rs.3.rs-166939/v1

License: (1) (1) This work is licensed under a Creative Commons Attribution 4.0 International License. Read Full License 


\section{Abstract}

Many personal care products integrate UV-filters, such as 4-methylbenzylidene camphor (4-MBC) which has been detected in aquatic habitats. Possible effects of 4-MBC to aquatic organisms have been poorly studied. Therefore, the main objective of this work is to study the effects of 4-MBC exposure to Solea senegalensis during metamorphosis, a sensitive life stage of this flatfish. To achieve this, at the beginning of metamorphosis (13 days after hatching, dah) fish were exposed to 4-MBC (0.2-2.0 mg L-1) for $48 \mathrm{~h}$. After this period, fish were transferred to clean medium and were fed and maintained until more than $80 \%$ of fish in control group completed the metamorphosis (24 dah). Mortality, malformations and metamorphosis progression were studied on a daily basis. In addition, growth, behavior and biochemical markers of neurotransmission (acetylcholinesterase, AChE), oxidative stress (catalase, CAT; glutathione S-transferase, GST, and lipid peroxidation, LPO) and anaerobic metabolism (lactate dehydrogenase, LDH) were determined at the end of the experiment. An acceleration of metamorphosis progression was observed during and 2 days after the 4-MBC exposure in all concentrations tested. In addition, decreased length, inhibition of CAT activity and induction of oxidative damage (LOEC $=0.928 \mathrm{mg} \mathrm{L}^{-1} 4-\mathrm{MBC}$ for length, CAT and LPO) were observed. A short-term exposure to 4-MBC at the onset of metamorphosis, a critical period of development, affected $S$. senegalensis at several levels of organization, even after nine days in clean medium, including growth and metamorphosis progression, suggesting possible long-term adverse effects to this species.

\section{Introduction}

Harmful effects of UV reaching the Earth surface is leading to growing consumption of sunscreens, which results in the increasing presence of their ingredients in the environment (Lowe, 2006; Young, 2006; Young et al., 2017). Early life stages of coastal and marine species can be highly exposed to these chemical compounds, since most part of world population lives and uses such chemical products near aquatic habitats (Shoji et al., 2011; Tovar-Sánchez et al., 2013; Pimentel et al., 2015; Wen et al., 2017a).

Organic UV filters are amongst the key ingredients of personal care products (PCPs), including sunscreens. Therefore, contamination of coastal areas by PCPs is receiving increasing attention (e.g. Tovar-Sánchez et al., 2013; Chisvert and Salvador, 2018; Capela et al., 2019). The 4-methylbenzylidene camphor (4-MBC) is one of the most used UV filters (Krause et al., 2012; Wang et al., 2016; Chisvert and Salvador, 2018). As a consequence, this compound is present in bathing areas, mainly during daylight and warmer months, reaching concentrations up to $1.043 \mu \mathrm{g} \mathrm{L}^{-1}$ in Atlantic Gran Canaria (SánchezRodríguez et al., 2015). 4-MBC can also reach aquatic ecosystems through the release of untreated or ineffectively treated effluents from wastewater treatment plants (Balmer et al., 2005; Li et al., 2007; Langford and Thomas, 2008; USEPA, 2012; Sánchez-Rodríguez et al., 2015). This highly stable and lipophilic compound, suffers low biotic degradation and has high potential for adsorption to bed sediments, presenting levels up to $7.6 \mathrm{ng} \mathrm{g}^{-1}$ dry weight of 4-MBC in beach sand of Porto coast (Portugal) 
(Capela et al., 2019) and is also bioaccumulated in aquatic organisms, including fish (e.g. Balmer et al., 2005; Buser et al., 2006; Gago-Ferrero et al., 2012).

Previous works have shown that 4-MBC affects development, behavior and biochemical endpoints during larval stages of amphibians (Martins et al., 2017) and freshwater (Li et al., 2016; Torres et al., 2016; Quintaneiro et al., 2019) or marine fish (Araújo et al., 2018). Endocrine action of 4-MBC has been previously reported (Krause et al., 2012; Ozáez et al., 2013; Wang et al., 2016), which included androgen and oestrogen activity and effects on reproductive organs. In addition, effects on thyroid axis of vertebrates have also been reported, which included increased thyroid weight, altered thyroid hormones levels and decreased iodide uptake (Gotthardt et al., 2007; Krause et al., 2012).

Flatfish, such as Senegalese sole (Solea senegalensis Kaup, 1858), have been increasingly used in European marine aquaculture industry (Imsland et al., 2003; Morais et al., 2016). Besides, their complex and fast life cycle are interesting for ecotoxicological studies (Pimentel et al., 2015; Pavlaki et al., 2016; Araújo et al., 2018; 2019; 2020). The eggs can be obtained from wild spawners in rearing facilities in Southern Europe throughout the year (Imsland et al., 2003; Anguis and Cañavate, 2005; Morais et al., 2016). This species typically hatch at 38 hours post fertilization (hpf) and after the thyroid-mediated metamorphosis (10 to 15 days after hatching, dah) the organisms become laterally asymmetric and benthic (Yúfera et al., 1999; Klaren et al., 2008; Sarasquete et al., 2019). The metamorphosis of $S$. senegalensis ends at nearly three weeks of life and is a fast and deep morphologically and biochemically changing stage in flatfish life history. Additionally, the circadian rhythm of this species also changes during metamorphosis: their activity is higher during day light before metamorphosis; while after this event the organism becomes nocturnal (Blanco-Vives et al., 2012). Previous studies have shown that metamorphosis of $S$. senegalensis can be affected by environmental conditions such as temperature (Campos et al., 2013) and feeding conditions (Fernández-Diáz et al., 2001). The progression of metamorphosis is directly regulated by the fluctuation of thyroid hormones levels (Yamano et al., 1991; Okada et al., 2003; Klaren et al., 2008). Therefore, chemicals might interfere with thyroid axis, namely those having structural similarity with thyroid hormones, or by interfering in their synthesis, transport and/or metabolism (Crofton, 2007; 2008; Veldhoen et al., 2006; Luthe et al., 2008; Sowers and Klaine, 2008). Flatfish metamorphosis has been reported to be affected by the exposure to chemical stressors with endocrine disrupting properties by retarding the metamorphic process (Dong et al., 2017) or increasing thyroid hormone levels and/or inducing faster metamorphosis progression (Yue et al., 2017; Araújo et al., 2019).

Behavior can be integrated with responses at lower (e.g. physiological) or higher levels of organization (e.g. populations) and is among the most sensitive endpoints with increasing use in ecotoxicology (Scott and Sloman, 2004; Vieira et al., 2009; Sloman and McNeil, 2012; Almeida et al., 2015; Henriques et al., 2016; Araújo et al., 2018; 2020; Sharma, 2019). Previous studies have shown that $S$. senegalensis behavior during early pelagic stage was affected by 4-MBC exposure (Araújo et al., 2018); however, the effects of the exposure to this chemical during metamorphosis, a sensitive window of flatfish development is still unknown. 
Biochemical markers are commonly used on evaluation of stressors effects at molecular level. Their changes might be associated with effects at higher level of biological organization, such as behavior and fish growth and can provide information to understand the mechanisms and modes of action of stressors (Oost et al., 2003). Acetylcholinesterase (AChE) is one main neurotransmission enzymes that can work as biomarker. Organic compounds such as the UV filter 4-MBC have also been shown to inhibit AChE (Li et al., 2016). Previous results with S. senegalensis during early pelagic stage were unclear to associate exposure of 4-MBC with behavioral and anticholinergic activity (Araújo et al., 2018) and information about the effects of this chemical during metamorphosis progression are still lacking. The oxidative stress caused by reactive oxygen species can be detected through determination of increased antioxidant enzymes activity (such as catalase, CAT or glutathione S-transferase, GST). The study of molecular and enzymatic responses to 4-MBC exposure already showed that this compound affects the antioxidant system of different aquatic species (Gao et al., 2013; Campos et al., 2017a; Martins et al., 2017). The GST and CAT have a central role on oxidative stress response and also these enzyme levels fluctuate in response to organisms physiological or developmental stages including during metamorphosis (Oost et al., 2003; Menon and Rozman, 2007; Rudneva et al., 2010; Araújo et al., 2019). Lipid peroxidation (LPO) can be observed when antioxidant capacity of organisms is surpassed. Peroxidation can occur in lipids of cell membranes as result of exposure to of different classes of stressors (Oost et al., 2003). Under stress conditions, lactacte dehydrogenase (LDH) enzyme activity can be used as biomarker since anaerobic metabolism might be switched on due to increased energy demand such as detoxification mechanisms to cope with exposure to chemical stressors (Diamantino et al., 2001; Güngördü et al., 2016; Wen et al., 2017a).

Studies on the effects of environmental contaminants such as UV-filters on key stages of life cycle of marine vertebrates, in particular during the thyroid-regulated metamorphosis of $S$. senegalensis, linking biochemical, physiological and morphological effects from sub-cellular to organism level are still lacking. In this context, the objective of this work is to study the effects of 4-MBC exposure during metamorphosis, a sensitive period of this flatfish early development, at different levels of biological organization. Effects on mortality, development, metamorphosis progression, growth, behavior and biochemical markers were evaluated.

\section{Material And Methods}

\subsection{Chemicals}

The 4-MBC was purchased from Sigma-Aldrich Co. LLC (St Louis, USA) and the ethanol used to prepare 4MBC stock solution and solvent control was supplied by Merck. All other chemicals used in biochemical marker analysis were of analytical grade quality and were also purchased from Sigma-Aldrich Co., except the protein assay kit, which was purchased from Bio-Rad (Germany).

\subsection{Biological material and experimental design}


Eggs from a commercial aquaculture in north of Portugal (Safiestela/Sea8, Póvoa de Varzim) were brought to laboratory within 12 hours of fertilization and placed in a recirculating system equiped with one $25 \mathrm{~L}$ fiber tank, biological filtering medium, UVR sterilizer, protein skimmer. The flow rate in the main tank increased with fish age refrigeration unit set at $19^{\circ} \mathrm{C}$ and room light photoperiod at $16 \mathrm{~h}: 8 \mathrm{~h}(\mathrm{l}: \mathrm{d})$. Medium was composed by artificial saltwater (35 of salinity, Coral Pro salt, Saudi Arabia), daily feeding included rotifers (Brachionus plicatilis, from 2 dah until 6 dah in increasing concentrations between 5 and 10 rotifers $\mathrm{mL}^{-1}$ ) and Artemia salina nauplii and metanauplii (from 5 until 10 between 2 and 9 nauplii $\mathrm{mL}^{-1}$ and from 9 until 13 dah between 9 up to 35 metanauplii $\mathrm{mL}^{-1}$, respectively). The microalgae Nannochloropsis gaditana was also provided daily for improvement of maintenance conditions (Brown \& Blackburn, 2013).

The beginning of the metamorphosis was evaluated in accordance with morphological features of fish (Yúfera et al., 1999; Fernández-Díaz et al., 2001; Araújo et al., 2019), which occurred at 13 dah. At this age, fish had a total length of $4.7 \pm 0.23 \mathrm{~mm}$ ( $\mathrm{n}=24$; random measurement). Randomly selected organisms were then exposed to concentrations of $4-\operatorname{MBC}\left(0.200,0.294,0.431,0.632,0.928,1.363\right.$ and $2.000 \mathrm{mg} \mathrm{L}^{-}$ $\left.{ }^{1}\right)$ and respective controls in glass petri dishes $(n=6,5$ fish per biological replicate/petri dish, $10 \mathrm{~mL}$ of testing solution per replicate). The choice of the concentration range was based on the dose-response effects of 4-MBC in earlier life stages of S. senegalensis from previous work (Araújo et al., 2018). These concentrations are higher than expected in saltwater natural ecosystems but were applied during a short duration of exposure, chosen to fit the onset of metamorphosis and to mimic an high contaminant input during summer season.

The testing solutions were prepared by dilution of a stock solution of 4-MBC in ethanol $\left(20 \mathrm{mg} \mathrm{mL}^{-1}\right)$ in artificial saltwater (Coral Pro salt). A negative control (only saltwater) and a solvent control (ethanol in saltwater at $0.01 \% \mathrm{v} / \mathrm{v}$, as used in the highest tested concentration of $4-\mathrm{MBC}$ ) were also used. The $\mathrm{pH}$ of 4-MBC solutions ranged between 8.10 and 8.25 ( 8.06 for solvent control and 8.17 for negative control) while the salinity ranged between 33.8 and 35.5 for 4-MBC testing solutions (34.2 for solvent control and 34.6 for negative control). The bioassay was performed with an oxygen saturation level over $80 \%$.

During a period of $48 \mathrm{~h}$, exposure to testing solutions was performed with no feeding of fish. After that period, fish were transferred to six well plastic plates with clean artificial saltwater medium $(10 \mathrm{ml})$ and fed daily with artemia metanauplii until 24 dah. Artificial saltwater was also renewed daily. At 24 dah, the experiment was stopped as more than $80 \%$ of fish from negative and solvent control groups completed the metamorphosis $(93 \pm 6.7 \%$ and $80 \pm 5.8 \%$ respectively). Fish were then snap frozen in liquid nitrogen and kept at $-80^{\circ} \mathrm{C}$ until biochemical analysis. The test was performed in a room with controlled temperature $\left(T=19^{\circ} \mathrm{C}\right)$. All experimental procedures were carried out following the European and Portuguese legislation concerning animal experimentation and authorized by the Portuguese competent authority (Direcção Geral de Alimentação e Veterinária, Ref. 009804).

\subsection{Apical and developmental endpoints}


Mortality, malformations, development effects and metamorphosis development stages were recorded daily during exposure to 4-MBC and until the end of the experiment with a stereoscope in all sampling groups and replicates. Metamorphosis development stages of fish were determined in accordance with literature (Dinis, 1986; Fernández-Díaz et al., 2001; Klaren et al., 2008; supplementary table S1). Length of organisms in each experimental group was determined at the end of metamorphosis $(n=6,3$ fish per replicate).

\subsection{Behavior analysis}

Effects of 4-MBC exposure on behavior of $S$. senegalensis was studied at the end of the metamorphosis (at 24 dah). The Zebrabox ${ }^{\circledR}$ (Viewpoint, France) was used to record behavioral response $(n=6,1$ randomly selected organism from each biological replicate) in 24 well plates with $2 \mathrm{~mL}$ of clean medium in each well (1 organism per well). Behavior was analysed after an initial 5 min acclimation period (light), during four alternate light (L)-dark (D) periods (LDLD) with 15 min each. Zebralab software (Viewpoint) recorded movement as total swimming duration and distance (integration periods of 1 minute). Background threshold was set at 60 pixels, and light intensity at $10 \%\left(0.26 \mathrm{~mW} \mathrm{~cm}^{-2}\right)$. For recording purposes, this device also irradiates a constant infrared light $\left(2.30 \pm 0.11 \mathrm{~mW} \mathrm{~cm}^{-2}\right)$.

\subsection{Biochemical analysis}

Previously frozen samples ( $n=6$, pools of 3-5 fish from each biological replicate) were used to measure the activity of the enzymes AChE, CAT, GST, LDH and LPO levels in fish at the end of metamorphosis. Samples were initially homogenized with potassium buffer solution $(\mathrm{pH}=7.4,0.1 \mathrm{M}, 150 \mu \mathrm{L}$ per organism) by sonication. An aliquot of tissue homogenate was separated into a microtube with $4 \mu \mathrm{L}$ of $4 \%$ butylated hydroxytoluene (BHT) in methanol and was used for LPO determination by measuring thiobarbituric acidreactive substances (TBARS) at $535 \mathrm{~nm}$ (Bird and Draper, 1984). The remaining homogenate was centrifuged during $20 \mathrm{~min}$ at $10,000 \mathrm{~g}\left(4^{\circ} \mathrm{C}\right)$ and the supernatant was used for the following enzymatic analyses and protein quantification. AChE activity was quantified by using acetylthiocholine as substrate and 5-5'-dithiobis (2-nitrobenzoic acid) (DTNB) as chromogen and measuring the increase of absorbance at $414 \mathrm{~nm}$ (Ellman et al., 1961; Guilhermino et al., 1996). CAT activity was determined by measuring the rate of hydrogen peroxide $\left(\mathrm{H}_{2} \mathrm{O}_{2}\right)$ consumption at $240 \mathrm{~nm}$ (Clairborne, 1985). LDH activity was determined following the methodology of Vassault (1983) with the modifications introduced by Diamantino et al. (2001) by measuring the conversion of pyruvate to L-lactate with the concomitant conversion of NADH to NAD+ during glycolysis which is monitored at $340 \mathrm{~nm}$. GST activity was measured following the conjugation of glutathione (GSH) with 1-chloro-2,4-dinitrobenzene (CDNB) at 340 nm (Habig and Jakoby, 1981; Frasco and Guilhermino, 2002). The protein concentration was determined in triplicate according to the Bradford method (Bradford, 1976), adapted to microplate from BioRad's Bradford protein micro-assay kit, using bovine y-globuline as a standard and a wavelength of $595 \mathrm{~nm}$. The enzymatic activity is expressed in Units $(U)$ per $\mathrm{mg}$ of protein where one $\mathrm{U}$ is a nmol of substrate 
hydrolyzed per minute, using a molar extinction coefficient of $13.6 \times 10^{3} \mathrm{M}^{-1} \mathrm{~cm}^{-1}$ for AChE and $9.6 \times 10^{3} \mathrm{M}^{-}$ ${ }^{1} \mathrm{~cm}^{-1}$ for GST and $\mathrm{U}$ is one $\mu \mathrm{mol}$ of substrate hydrolyzed per minute, using a molar extinction coefficient of $40 \mathrm{M}^{-1} \mathrm{~cm}^{-1}$ for CAT and $6.3 \times 10^{3} \mathrm{M}^{-1} \mathrm{~cm}^{-1}$ for $\mathrm{LDH}$. The LPO is expressed in nmol of TBARs hydrolyzed per mg protein using a molar extinction coefficient of $1.56 \times 10^{5} \mathrm{M}^{-1} \mathrm{~cm}^{-1}$. Spectrophotometric determinations were performed in 96 well microplates (3-4 technical replicates per sample) using a Labsystem Multiskan EX.

\subsection{Statistical analysis}

Three-parameter logistic regression were performed for mortality and malformations at 14, 15 and 24 dah. After initial t-test for testing existence of differences between solvent and negative control, One-way ANOVA were used to verify differences between solvent control and 4-MBC treatment groups for length, biochemical effects and behaviour (total duration and distance of swimming). When normality or equality of variance of were not achieved, Kruskal-Wallis test (one-way non-parametric ANOVA) was used. When significant differences were found, post-hoc Dunnett's pairwise tests against solvent control were performed. Further statistical analysis of behaviour was performed, testing the effect of 4-MBC concentrations and the response to light and dark cycles with two-way Repeated Measures ANOVA.

Effects of 4-MBC on metamorphosis progression were studied using Chi-Square test, followed by pairwise Chi-square test for detection of significant differences between 4-MBC groups and solvent control, with Bonferroni adjustment (Arnholt, 2016).

Sigmaplot v.12.5 (Systat Software, Inc.) was used for all statistical procedures and all results are expressed as mean \pm standard error.

\section{Results}

\subsection{Mortality and malformations}

Fish mortality was $0 \%$ in solvent and negative controls along the test. Increasing mortality was observed in fish groups during exposure to 4-MBC (fig. 1A). The highest mortality occurred in fish exposed to 2.000 $\mathrm{mg} \mathrm{L}^{-1} 4-\mathrm{MBC}$ at 15 dah $(70.0 \pm 8.56 \%)$, wich after changing to clean medium, did not increase until the end of metamorphosis at 24 dah. At the end of metamorphosis, the $L_{20}$ was $1.442 \mathrm{mg} \mathrm{L}^{-1}(95 \%$ confidence interval, c.i.: 1.234-1.816, Supplementary table S2).

No malformations were observed in fish from both controls groups during exposure to 4-MBC and until complete metamorphosis. Alterations to normal fish development were observed in fish exposed up to $2.000 \mathrm{mg} \mathrm{L}^{-1}$ of $4-\mathrm{MBC}$, mainly during the $48 \mathrm{~h}$ exposure period with a $\mathrm{LC}_{20}$ of 0.883 (c.i.: $0.617-1.219$ ) $\mathrm{mg}$ $\mathrm{L}^{-1}$ and 1.044 (c.i. $\left.0.750-1.399\right) \mathrm{mg} \mathrm{L}^{-1}$ at 14 dah and 15 dah, respectively (fig. 1B). The malformations decreased after nine days in clean media ( $\left(\mathrm{CC}_{20}\right.$ at that time was over $\left.1.363 \mathrm{mg} \mathrm{L}^{-1}\right)$ while mortality did not 
increase during the same period. Malformations observed refer to the simultaneous alterations on skin pigmentation, fin and abdominal cavity (fig. 2). Only fish groups exposed up to and including $1.363 \mathrm{mg} \mathrm{L}^{-}$

1 were used to assess the remaining endpoints.

\subsection{Metamorphosis}

Significant differences between negative and solvent control fish were observed when analysing the distribution of relative percentages of fish in each metamorphic stage (A to $G$ ) with solvent control fish constantly presenting retarded metamorphic progress comparing to negative control at 14, 17, 20, 22 and 24 dah ( $p<0.05$, Chi-square test, fig. S1).

Significant differences on relative percentages of fish in each metamorphic stage were observed between solvent control and all groups of fish exposed to 4-MBC at 14 dah (24h of 4-MBC exposure) and 17 dah ( 2 days after the end of 4-MBC exposure), with 4-MBC exposed fish groups presenting faster metamorphosis progression than fish in solvent control group $(p<0.05$, fig. 3$)$. However, at 20 dah and afterwards, such faster development is absent and fish exposed to the highest 4-MBC concentration tested (1.363 $\left.\mathrm{mg} \mathrm{L}^{-1}\right)$ presented even a retarded metamorphic progress compared to solvent control fish $(\mathrm{p}<0.05)$. In addition, at 22 and 24 dah, fish exposed to $0.431 \mathrm{mg} \mathrm{L}^{-1} 4-\mathrm{MBC}$ presented also retarded metamorphic progress compared to fish from solvent control $(p<0.05)$.

\subsection{Length}

There were no significant differences on total length of fish between solvent control $(8.6 \pm 0.14 \mathrm{~mm})$ and negative control $(8.6 \pm 0.21 \mathrm{~mm})$ at the end of metamorphosis, at 24 dah $(p>0.05)$. Exposure to $4-\mathrm{MBC}$ induced a significant decrease in length of fish exposed to the two highest concentrations tested, 0.928 $\mathrm{mg} \mathrm{L}^{-1}$ and $1.363 \mathrm{mg} \mathrm{L}^{-1}$, with fish presenting $6.9 \%$ and $11.6 \%$ of reduction in length in relation to fish in solvent control, respectively $(\mathrm{p}<0.05$, fig. 4$)$.

\subsection{Behavior}

When analysing the effect of 4-MBC on behaviour at 24 dah during the $60 \mathrm{~min}$. in each $15 \mathrm{~min}$. light or dark periods, significant differences on swimming duration and distance between controls and between solvent control and 4-MBC treatment groups were not observed ( $p>0.05$, fig. S2). Nonetheless, light absence seems to induce a general significant increasing trend for swimming distance $(p<0.05)$. The interaction of both factors (4-MBC and light/dark) for both parameters (swimming distance and duration) was not significant $(p>0.05)$.

No significant differences were observed between negative and solvent controls on total duration of swimming ( $19.8 \pm 4.75$ and $18.2 \pm 3.08 \mathrm{~min}$, respectively) and total swimming distance $(70.2 \pm 11.79$ and $55.4 \pm 12.66 \mathrm{~m}$, respectively, $\mathrm{p}>0.05)$. An increasing trend in the total swimming duration and distance was 
observed on fish exposed to the lowest 4-MBC concentrations tested, with significantly higher swimming distance registered in fish exposed to $0.294 \mathrm{mg} \mathrm{L}^{-1}$ of $4-\mathrm{MBC}$ when comparing to solvent control $(p<0.05$, fig. 5).

\subsection{Biochemical markers}

The effects of 4-MBC exposure on S. senegalensis biochemical markers analysed at the end of metamorphosis are presented in fig. 6. No significant differences were obtained for AChE, CAT, GST enzymatic activities and LPO levels between fish from negative and solvent control groups $(p>0.05)$. On the contrary, LDH activity of fish from solvent control group $\left(0.172 \pm 0.0023 \mathrm{U} \mathrm{mg}\right.$ of protein $\left.{ }^{-1}\right)$ was significantly lower than in fish from negative control $\left(0.190 \pm 0.0042 \mathrm{U} \mathrm{mg}\right.$ of protein $\left.{ }^{-1}, p<0.05\right)$.

Exposure to 4-MBC did not induce alterations in AChE, GST nor in LDH activity of fish exposed to 4-MBC when comparing with fish in solvent control group $(p>0.05)$.

Considering the oxidative stress biomarkers analysed, exposure to 4-MBC inhibited the activity of CAT, with significant lower activity recorded in the two highest concentrations tested, namely in $0.928 \mathrm{mg} \mathrm{L}^{-1}$ and $1.363 \mathrm{mg} \mathrm{L}^{-1}$ of $4-\mathrm{MBC}$, corresponding to a decrease in activity of $19.8 \%$ and $26.1 \%$, respectively $(p<0.05)$. Fish exposed to these concentrations also presented significantly higher LPO levels, corresponding to an increase of $89.7 \%$ and $77.1 \%$, respectively, in relation to solvent control $(p<0.05)$.

\section{Discussion}

In the present work, we aimed at studying effects of exposure to 4-MBC during $S$. senegalensis metamorphosis at different levels of organization. Metamorphosis is a high demanding energetic and sensible period in the development of flatfish species. Therefore, exposure to 4-MBC during a relatively short period of time, concomitantly to the onset of metamorphosis represents an additional challenge to the normal development of sole. Although, the exposure to lower concentrations for longer periods would be more realistic, the studied 4-MBC concentrations and conditions provided relevant insights on mechanisms of toxicity and recovery of sole early life stages. Indeed, deleterious effects were observed during exposure to 4-MBC (table 1), but also at the end of metamorphosis, nine days after the exposure ended, suggesting lasting and/or lagged effects of 4-MBC in this species.

\subsection{Apical and developmental endpoints}

The mortality observed with $S$. senegalensis exposed to 4-MBC at the onset of metamorphosis indicate that $S$. senegalensis in this life stage is less sensitive to 4-MBC than earlier life stages. In a previous work with $S$. senegalensis eggs, after $48 \mathrm{~h}$ exposure to $0.935 \mathrm{mg} \mathrm{L}^{-1}$ of 4-MBC (highest concentration tested) mortality was $40.0 \pm 16.96 \%$ and a $96 \mathrm{~h}-\mathrm{LC}_{50}$ of $0.439 \mathrm{mg} \mathrm{L}^{-1} 4-\mathrm{MBC}$ was obtained (Araújo et al., 2018). Whereas, in the present work, the mortality observed in metamorphosing sole was lower than $15 \%$ for 
concentrations up to $1.363 \mathrm{mg} \mathrm{L}^{-1}$ (48h exposure). Nevertheless, metamorphosing $S$. senegalensis is more sensitive to 4-MBC than other aquatic vertebrate species, including zebrafish embryos, as an $72 \mathrm{~h}-$ $\mathrm{LC}_{50}$ of $5.042 \mathrm{mg} \mathrm{L}^{-1} 4-\mathrm{MBC}$ was reported by Li et al. (2016) and concentrations up to $1.3 \mathrm{mg} \mathrm{L}^{-1} 4-\mathrm{MBC}$ did not affect survival of the frog Pelophylax perezi larvae during 144h exposure (Martins et al., 2017).

The exposure to stressors can induce alterations on metamorphosis progression and lead to permanent or short-temporal abnormalities such as lack and/or erratic eye migration or bone deformities in metamorphosing S. senegalensis (Araújo et al., 2019). In the present work, 4-MBC induced malformations to $S$. senegalensis, which have occurred during the initial $48 \mathrm{~h}$ exposure period of the bioassay. Such malformations might be related with the effects observed on metamorphosis progression and fish growth, as the total number of organisms that completed metamorphosis and their total length were still affected by 4-MBC exposure by the end of metamorphosis, at 24 dah. Delayed development caused by 4MBC exposure has been reported in amphibian larvae (Martins et al., 2017). Such effects of 4-MBC on normal mechanisms of development of aquatic vertebrate species still needs further study.

A faster progression of metamorphosis was observed in fish exposed to 4-MBC at the beginning of the metamorphic phase, during the exposure and immediately after the two day exposure. Despite the solvent used (ethanol at $0.01 \% \mathrm{v} / \mathrm{v}$ ) delayed metamorphosis progression of $S$. senegalensis in relation to negative control, the exposure to some concentrations of 4-MBC induced a further progression delay at the end of metamorphosis when comparing with solvent control. Normal progression of flatfish and anuran metamorphosis are known to be affected by the exposure to other chemicals, some of them with endocrine disruptor potential (e.g. Dong et al., 2017; Yue et al., 2017; Araújo et al., 2019). For instance, our previous work with $S$. senegalensis using a similar experimental design, showed that the exposure to the wide spectrum biocide triclosan (TCS) induced an immediate acceleration of the metamorphosis while no effects were observed at the end of metamorphosis (Araújo et al., 2019). While TCS is reported to have a similar structure to the thyroid hormone thyroxine, since both are halogenated biphenyl ethers (Crofton et al., 2007), such similarity is not so clear with 4-MBC. Nevertheless, specific effects by 4-MBC on organs or tissues associated with thyroid function have also been previously reported and associated with pro or anti-thyroid action (Gotthardt et al., 2007; Schmutzler et al., 2007; Wang et al., 2016). In addition, it should also be mentioned that in the present work, some fish groups exposed to 4-MBC presented a lower rate of fish with complete metamorphosis at 24 dah when comparing to control groups, indicating lasting effects of this chemical since exposure to this chemical was interrupted nine days earlier. Therefore, the mechanism by which this occurs needs to be studied in order to verify if there is any relation with a medium or long-term possible interference in the thyroid axis, which regulates metamorphosis in sole. Furthermore, the morphological effects of 4-MBC on metamorphosis indicate possible occurrence of lasting ecological implications that can be anticipated as severe and should be further studied. Longer exposure periods to lower concentrations of 4-MBC (environmental relevant) may affect differently development and metamorphosis progression and should be considered in further studies.

Growth of S. senegalensis was affected in the present study in response to exposure to 4-MBC. Growth of S. senegalensis was also affected by $4-\mathrm{MBC}$ after $96 \mathrm{~h}$ exposure period carried out in an earlier life stage 
with the same species (Araújo et al., 2018). The lowest observed effect concentration (LOEC) on length in the earlier life stage was $0.360 \mathrm{mg} \mathrm{L}^{-1} 4-\mathrm{MBC}$ and $-0.928 \mathrm{mg} \mathrm{L}^{-1} 4-\mathrm{MBC}$ in present test conditions (48h exposure followed by 9 days in clean medium). This results seem to follow the generally observed decrease of sensitivity to chemicals with fish increasing age which was also observed in $S$. senegalensis with another chemical stressor, namely TCS (Araújo et al., 2019). A short exposure period of exposure to 4-MBC was performed (48h) in the present study than in earlier stage test (96 h) (Araújo et al., 2018) and longer periods of exposure to lower 4-MBC levels could induce furtherdecrease of the LOEC. In addition, attention should also be given to the fact that length measurement was only performed nine days after maintenance in clean medium and feeding, demonstrating lasting effects of this chemical on the normal development of this species, which can have further implications at higher levels of organization.

\subsection{Behavior}

In the present work, effects of 4-MBC on S. senegalensis behavior were observed at the end of the metamorphosis. Namely, for the lower concentrations tested $\left(0.294 \mathrm{mg} \mathrm{L}^{-1} 4-\mathrm{MBC}\right)$ an increase of fish swimming behavior was observed, even after nine days in clean medium after the exposure to 4-MBC. However, in previous studies a distinct effect of 4-MBC on behavior was observed in earlier life stages of sole (Araújo et al., 2018); a significant decrease on total sole swimming time was observed in fish exposed to the highest concentration tested, $0.360 \mathrm{mg} \mathrm{L}^{-1}$ 4-MBC (Araújo et al., 2018). In addition, Li et al. (2016) have reported an impairment of swimming of zebrafish embryos with exposure to $3.81 \mathrm{mg} \mathrm{L}^{-1} 4$ MBC.

Different distinct activity patterns are expected to be observed on S. senegalensis depending on life stage, with metamorphosis inducing a change to higher nocturnal activity while early larvae are diurnal (Bayarri et al., 2004; Blanco-Vives et al., 2011, 2012). The different swimming activity pattern of metamorphosing sole in response to 4-MBC in relation to earlier life stages, might be due to the distinct behavioral patterns of each life stage of $S$. senegalensis.

Swimming is a major component of energy expenditure for many fishes (McKenzie, 2011). The increased energy used by $S$. senegalensis exposed to lower $4-\mathrm{MBC}$ through increased swimming distance can be associated with effects on energetic budget. In fact, effects of chemical stressors on energetic balances have already been reported (Agbohessi et al., 2014; Rabasa and Dickson, 2016; Anacleto et al., 2018). Such excitatory swimming response after 4-MBC exposure may also have later implications on growth or successful feeding and reproduction.

\subsection{Biochemical markers}

Biochemical endpoints were studied with post-metamorphic $S$. senegalensis nine days after exposure to 4-MBC. In the present study, effects on AChE activity levels were not detected at the end of the experiment after exposure to 4-MBC. Similarly, previous studies also reported the inexistence of neurotoxic effects of 
this chemical in other species, namely on freshwater caddisfly Sericostoma vittatum (Campos et al., 2017a), aquatic midge Chironomus riparius (Campos et al., 2017b) and embryos of the amphibian Pelophylax perezi after exposure to 4-MBC (Martins et al., 2017). On the contrary, induction of AChE by 4MBC was observed in Solea senegalensis early life stages (Araújo et al., 2018) and in zebrafish embryos (Quintaneiro et al., 2019). Such diverse responses should be further studied as 4-MBC is a camphor derivative and camphor's belong to the terpenes family, which are considered AChE inhibitors (Ahmed et al., 2013; Li et al., 2016). Additionally, 4-MBC exposure seem to induce different AChE activity patterns depending on the life stages of S. senegalensis (Araújo et al., 2018), and this was also observed with TCS exposure, while no effects were observed on sole 3 dah-larvae, an induction of AChE was observed in metamorphosing larvae (Araújo et al., 2019), reflecting different biochemical responses.

Alterations of AChE (whether as inhibition or induction) under stress conditions can be associated with effects at behavioral level (Mach et al., 2004; Rao et al., 2005; García-de-la-Parra et al., 2006; Li et al., 2016; Araújo et al., 2018). However, in the present work, the increase in swimming activity observed with 4-MBC cannot be related with an alteration in AChE activity. The 4-MBC increased fish swimming distance at $0.294 \mathrm{mg} \mathrm{L}^{-1}$, suggesting an excitatory effect at the lower concentrations tested, but no significant alteration on AChE was detected, despite the slightly higher activity registered in all 4-MBC concentrations.

In the present study, CAT activity was inhibited in S. senegalensis exposed to the highest concentrations of 4-MBC tested and increased LPO levels occurred at the same concentrations, indicating the occurrence of oxidative damage. During metamorphosis of amphibians (Tata, 1994; Kashiwagi et al., 1999) and flatfish (Fernández-Díaz et al., 2006; Yu et al., 2006; Klaren et al., 2008; Power et al., 2008; Sun et al., 2015; Araújo et al., 2019), CAT levels are expected to fluctuate in response to programmed cell death. The exposure to 4-MBC induced effects on S. senegalensis, inhibiting normal CAT activity levels by the end of fish metamorphosis, reflecting an impairment of the role of this enzyme in the antioxidant system, which might have contributed to the oxidative damage observed in lipids. Since our results indicate lasting oxidative damage by 4-MBC, even after 9 days in clean medium, awareness should be given to the fact that effects at higher levels of biological organization might appear or become observed in later life stages of these organisms (e.g. later juveniles or adult stages), which might impair their fitness (e.g. decreased resistance to disease, or feeding and preying success). Similarly to our results, exposure to 4MBC enhanced LPO levels in embryos of the frog P. perezi (Martins et al., 2017). However, no alterations in lipid peroxidation levels were observed after 4-MBC exposure in caddisfly Sericostoma vittatum since ROS detoxification might have occurred in this species as suggested in Campos et al. (2017a).

Previous studies with amphibian and zebrafish early life stages showed that GST activity was increased just after 4-MBC exposure (Martins et al., 2017; Quintaneiro et al., 2019). In the present work, GST levels were not affected. This might be associated with the period of fish maintenance in clean medium after 4MBC exposure before the biochemical analysis. Therefore, possible GST alterations in response to 4-MBC immediately after the $48 \mathrm{~h}$ exposure might have occurred, followed by a return to control levels at the end of metamorphosis. 
Variation of LDH can occur in response to changes on environmental conditions. Chemical stressors can also lead to LDH changes, which are related with toxicity effect on animal tissues and cells. Considering the effect of the solvent treatment on sole LDH, namely the observed inhibition of LDH activity in solvent control fish when comparing to negative control fish, this might be related with the fact that ethanol is a metabolic product that prevents lactate accumulation (Torres et al., 2012). Furthermore, when considering 4-MBC effects, and similarly to the results obtained in a toxicity test performed at earlier stages of $S$. senegalensis (Araújo et al., 2018) and a test using P. perezi embryos (Martins et al., 2017), no significant effect of 4-MBC on LDH activity was observed. These results suggest that 4-MBC exposure during the $S$. senegalensis early metamorphosis apparently do not induce alterations on anaerobic metabolism.

\subsection{Conclusions}

The present work showed that a 48h exposure to 4-MBC during the onset of metamorphosis affected $S$. senegalensis at different levels of biological organization, and part of these effects were observed even after nine days in clean medium. An acceleration of metamorphosis in all concentrations tested was observed during and just after the end of the exposure. Whereas, by the end of metamorphosis, 4-MBC showed in general to be able to retard metamorphosis progression, induce oxidative damage and inhibit growth in the highest concentrations tested in S. senegalensis. This indicates long-term effects of short exposure to this UV-filter during a critical period in the development of this marine species, which might have further implications at higher levels of organization. Moreover, the interference of 4-MBC in the progression of metamorphosis should be further studied in order to undestand if its mode of action is through the interference in the thyroid axis of this flatfish model.

\section{Declarations}

\section{Acknowledgments}

Thanks are due for the financial support to CESAM (UID/AMB/50017/2019), to FCT/MEC through national funds, and the co-funding by the FEDER, within the PT2020 Partnership Agreement and Compete 2020. The work of MJA was supported by Portuguese Foundation for Science and Technology (FCT) through the scholarship ref. SFRH/BD/52572/2014 and MSM is funded by national funds (OE), through FCT, I.P., in the scope of the framework contract foreseen in the numbers 4,5 and 6 of the article 23 , of the Decree-Law 57/2016, of August 29, changed by Law 57/2017, of July 19 . The authors also acknowledge Sea8 for providing S. senegalensis eggs and MSc. Abel Ferreira, Dr. Rui Rocha and Dr. Ricardo Calado for all the technical support and laboratory assistance.

\section{Ethics approval and consent to participate}

- Not applicable 


\section{Consent for publication}

- Not applicable

\section{Availability of data and materials}

- All data generated or analysed during this study are included in this published article [and its supplementary information files].

\section{Competing interests}

- The authors declare that they have no competing interests

\section{Funding}

- Thanks are due for the financial support to CESAM (UID/AMB/50017/2019), to FCT/MEC through national funds, and the co-funding by the FEDER, within the PT2020 Partnership Agreement and Compete 2020. The work of MJA was supported by Portuguese Foundation for Science and Technology (FCT) through the scholarship ref. SFRH/BD/52572/2014 and MSM is funded by national funds (OE), through FCT, I.P., in the scope of the framework contract foreseen in the numbers 4,5 and 6 of the article 23, of the Decree-Law 57/2016, of August 29, changed by Law 57/2017, of July 19.

\section{Authors' contributions}

- Mário J. Araújo: Conceptualization, Methodology, Investigation, Writing- Original draft preparation.

- Amadeu M.V.M. Soares: Supervision, Funding acquisition, Project administration.

- Marta S. Monteiro: Conceptualization, Investigation, Writing- Reviewing and Editing.

\section{References}

Agbohessi T.P., Toko I.I., N'tcha I., Geay F., Mandiki S.N.M., Kestemont P., 2014. Exposure to agricultural pesticides impairs growth, feed utilization and energy budget in African Catfish Clarias gariepinus (Burchell, 1822) fingerlings. International Aquatic Research, 6(4): 229-243.

Ahmed F., Ghalib R.M., Sasikala P., Ahmed K.K., 2013. Cholinesterase inhibitors from botanicals. Pharmacognosy Reviews, 7(14): 121-30. doi: 10.4103/0973-7847.120511. 
Almeida J.R., Gravato C., Guilhermino L., 2015. Effects of temperature in juvenile Seabass (Dicentrarchus labrax L.) biomarker responses and behaviour: implications for environmental monitoring. Estuaries and Coasts, 38: 45-55. doi: 10.1007/s12237-014-9792-7.

Anacleto P., Figueiredo C., Baptista M., Maulvault A.L., Camacho C., Pousão-Ferreira P., Valente L.M.P, Marques A., Rosa R., 2018. Fish energy budget under ocean warming and flame retardant exposure. Environmental Research, 164: 186-196. doi: 10.1016/j.envres.2018.02.023.

Anguis V., Cañavate J.P. 2005. Spawning of captive Senegal sole (Solea senegalensis) under a naturally fluctuating temperature regime. Aquaculture, 243(1-4): 133-145. doi: 10.1016/j.aquaculture.2004.09.026.

Araújo M. J., Rocha R.J.M., Soares A.M.V.M, Chisvert A., Monteiro M.S., 2018. Effects of UV filter 4methylbenzylidene camphor during early development of Solea senegalensis Kaup, 1858 . Science of the Total Environment, 628-629: 1395-1404. doi: 10.1016/j.scitotenv.2018.02.112.

Araújo M.J., Quintaneiro C., Soares A.M.V.M, Monteiro M.S., 2019. Effects of triclosan on early development of Solea senegalensis: from biochemical to individual level. Chemosphere, 235: 885-899.

Araújo M.J., Quintaneiro C., Soares A.M.V.M., Monteiro M.S., 2020. Effects of ultraviolet radiation to Solea senegalensis during early development. Science of the Total Environment. doi:

10.1016/j.scitotenv.2020.142899.

Arnholt A.T., 2016. Passion Driven Statistics. Available at https://alanarnholt.github.io.

Balmer M., Buser H.R., Muller M., Poiger T., 2005. Occurrence of some organic UV filters in wastewater, in surface waters, and in fish from Swiss lakes. Environmental Science \& Technology, 39: 953-962.

Bayarri M.J., Muñoz-Cueto J.A., López-Olmeda J.F., Vera L.M., Rol de Lama M.A., Madrid J.A., SánchezVázquez F.J., 2004. Daily locomotor activity and melatonin rhythms in Senegal sole (Solea senegalensis). Physiology \& Behavior, 81(4): 577-583.

Bird R.P., Draper H.H., 1984. Comparative studies on different methods of malonaldehyde determination. Methods in Enzymology, 105: 299-305.

Blanco-Vives B., Aliaga-Guerrero M., Cañavate J.P., García-Mateos G., Martín-Robles A.J., Herrera-Pérez P., Muñoz-Cueto J.A., Sánchez-Vázquez F.J., 2012. Metamorphosis induces a light-dependent switch in Senegalese sole (Solea senegalensis) from diurnal to nocturnal behavior. Journal of Biological Rhythms, 27: 135-144. doi: 10.1177/0748730411435303.

Blanco-Vives B., Aliaga-Guerrero M., Cañavate J.P., Muñoz-Cueto J.A., Sánchez-Vázquez F.J. 2011. Does lighting manipulation during incubation affect hatching rhythms and early development of sole? Chronobiology International, 28(4): 300-306. doi: 10.3109/07420528.2011.560316. 
Bradford M.M., 1976. A rapid and sensitive method for the quantitation of microgram quantities of protein utilizing the principle of protein-dye binding. Analytical Biochemistry, 72: 248-254.

Brown M.R., Blackburn S.I., 2013. Live microalgae as feeds in aquaculture hatcheries. In: Advances in Aquaculture Hatchery Technology (Editors: Geoff Allan and Gavin Burnell). Woodhead Publishing Series in Food Science, Technology and Nutrition. 117-156, 157e-158e. doi: 10.1533/9780857097460.1.117.

Buser H.R., Balmer M.E., Schmid P., Kohler M., 2006. Occurrence of UV filters 4-Methylbenzylidene camphor and octocrylene in fish from various Swiss rivers with inputs from wastewater treatment plants. Environmental Science \& Technology, 40(5): 1427-1431.

Campos C., Castanheira M.F., Engrola S., Valente L.M., Fernandes J.M., Conceição L.E., 2013. Rearing temperature affects Senegalese sole (Solea senegalensis) larvae protein metabolic capacity. Fish Physiology and Biochemistry, 39(6): 1485-1496. doi: 10.1007/s10695-013-9802-x.

Campos D., Gravato C., Fedorova G., Burkina V., Soares A.M.V.M., Pestana J.L.T., 2017a. Ecotoxicity of two organic UV-filters to the freshwater caddisfly Sericostoma vittatum. Environmental Pollution, 228: 370377. doi: 10.1016/j.envpol.2017.05.021.

Campos D., Gravato C., Quintaneiro C., Golovko O., Žlábek V., Soares A.M.V.M., Pestana J.L.T., 2017b. Toxicity of organic UV-filters to the aquatic midge Chironomus riparius. Ecotoxicology and Environmental Safety, 143: 210-216. doi: 10.1016/j.ecoenv.2017.05.005.

Capela D., Vila M., Llompart M., Dagnac T., García-Jares C., Alves A., Homem V., 2019. Footprints in the sand - Assessing the seasonal trends of volatile methylsiloxanes and UV-filters. Marine Pollution Bulletin, 140: 9-16. doi: 10.1016/j.marpolbul.2019.01.021.

Chisvert A., Salvador A., 2018. UV filters in sunscreens and other cosmetics: regulatory aspects and analytical methods. In: Salvador A., Chisvert A. (Eds.), Analysis of Cosmetics Products, second edition Elsevier, Amsterdam, pp. 85-106.

Clairborne A., 1985. Catalase activity. In: Greenwald R.A. (Ed.), CRC Handbook of Methods in Oxygen Radical Research, 283-284. CRC Press, Boca Raton, FL.

Crofton K.M., Paul K.B., Devito M.J., Hedge J.M., 2007. Short-term in vivo exposure to the water contaminant triclosan: Evidence for disruption of thyroxine. Environmental Toxicology and Pharmacology, 24(2): 194-197. doi: 10.1016/j.etap.2007.04.008.

Crofton K.M., 2008. Thyroid disrupting chemicals: mechanisms and mixtures. International Journal of Andrology, 31: 209-223. doi: 10.1111/j.1365-2605.2007.00857.x.

Diamantino T., Almeida E., Soares A.M.V.M., Guilhermino L., 2001. Lactate dehydrogenase activity as an effect criterion in toxicity tests with Daphia magna Straus. Chemosphere, 45(4-5): 553-560. doi: 10.1016/S0045-6535(01)00029-7. 
Dinis M.T., 1986. Quatre soleidae de l'estuaire du Tage. Reproduction et croissance. Essai d'elevage de Solea senegalensis Kaup. Université de Bretagne Occidentale. Brest. Ph.D. dissertation.

Dong Y., Zhang X., Tian H., Li X., Wang W., Ru S., 2017. Effects of polychlorinated biphenyls on metamorphosis of a marine fish Japanese flounder (Paralichthys olivaceus) in relation to thyroid disruption. Marine Pollution Bulletin, 119(1): 325-331. doi: 10.1016/j.marpolbul.2017.04.033.

Ellman G.L., Courtney K.D., Andres V., Featherstone R.M., 1961. A new and rapid colorimetric determination of acetylcholinesterase activity. Biochemical Pharmacology, 7(2): 88-95.

Fernández-Díaz C., Kopecka J., Cañavate J.P., Sarasquete C., Solé M., 2006. Variations on development and stress defences in Solea senegalensis larvae fed on live and microencapsulated diets. Aquaculture, 251: 573-584.

Fernández-Díaz D., Yúfera M., Cañavate J. P., Moyano F. J., Alarcón F. J., Díaz M., 2001. Growth and physiological changes during metamorphosis of Senegal sole reared in the laboratory. Journal of Fish Biology, 58(4): 1086-1097. doi: 10.1111/j.1095-8649.2001.tb00557.x.

Frasco M.F., Guilhermino L., 2002. Effects of dimethoate and beta-naphthoflavone on selected biomarkers of Poecilia reticulata. Fish Physiology and Biochemistry, 26(2): 149-156.

Gago-Ferrero P., Díaz-Cruz, M.S., Barceló D., 2012. An overview of UV-absorbing compounds (organic UV filters) in aquatic biota. Analytical and Bioanalytical Chemistry, 404: 2597-2610. doi: 10.1007/s00216012-6067-7.

Gao L., Yuan T., Zhou C., Cheng P., Bai Q., Ao J., Wang W., Zhang H., 2013. Effects of four commonly used UV filters on the growth, cell viability and oxidative stress responses of the Tetrahymena thermophila. Chemosphere, 93(10): 2507-2513. doi: 10.1016/j.chemosphere.2013.09.04.

García-de-la-Parra L.M., Bautista-Covarrubias J.C, Rivera-de la Rosa N., Betancourt-Lozano M, Guilhermino L., 2006. Effects of methamidophos on acetylcholinesterase activity, behavior, and feeding rate of the white shrimp (Litopenaeus vannamei). Ecotoxicology and Environmental Safety, 65(3): 372380 .

Gotthardt I., Schmutzler C., Kirschmeyer P., Wuttke w., Jarry H., Köhrle J. 2007. 4-methylbenzylidenecamphor (4MBC) causes effects comparable to primary hypothyroidism. Experimental and Clinical Endocrinology \& Diabetes, 115: P02_014. doi: 10.1055/s-2007-972421-

Guilhermino L., Lopes M.C., Carvalho A.P., Soares A.M.V.M. 1996. Inhibition of acetylcholinesterase activity as elect criterion in acute tests with juvenile Daphnia magna. Chemosphere, 32: 727-738.

Güngördü A., Uçkun M., Yoloğlu E., 2016. Integrated assessment of biochemical markers in premetamorphic tadpoles of three amphibian species exposed to glyphosate- and methidathion-based 
pesticides in single and combination forms. Chemosphere, 144: 2024-2035. doi:

10.1016/j.chemosphere.2015.10.125.

Habig W.H., Jakoby W.B. 1981. Assays for differentiation of glutathione S-transferases. Methods in Enzymology, 77: 398-405.

Henriques J.F., Almeida A.R., Andrade T., Koba O., Golovko O. Soares, A.M.V.M., Oliveira M., Domingues I., 2016. Effects of the lipid regulator drug gemfibrozil: A toxicological and behavioral perspective. Aquatic Toxicology, 170: 355-364. doi: 10.1016/j.aquatox.2015.09.017.

Imsland A.K., Foss A., Conceição L.E.C., Dinis M.T., Delbare D., Schram E., Kamstra A., Rema P., White P., 2003. A review of the culture potential of Solea solea and S. senegalensis. Reviews in Fish Biology and Fisheries, 13: 379-407.

Kashiwagi A, Hanada H., Yabuki M., Kanno T., Ishisaka R., Sasaki J., Inoue M., Utsumi K., 1999. Thyroxine enhancement and the role of reactive oxygen species in tadpole tail apoptosis. Free Radical Biology \& Medicine, 26(7-8): 1001-1009.

Kieffer J.D., 2000. Limits to exhaustive exercise in fish. Comparative Biochemistry and Physiology Part A: Molecular \& Integrative Physiology, 126(2): 161-179.

Klaren P.H.M, Wunderink Y.S., Yúfera M., Mancera J.M., Flik G., 2008. The thyroid gland and thyroid hormones in Senegalese sole (Solea senegalensis) during early development and metamorphosis. General and Comparative Endocrinology, 155: 686-694.

Krause M., Klit A., Blomberg-Jensen M., Søeborg T., Frederiksen H., Schlumpf M., Lichtensteiger W., Skakkebaek N.E., Drzewiecki K.T., 2012. Sunscreens: Are they beneficial for health? An overview of endocrine disrupting properties of UV-filters International Journal of Andrology, 35(3): 424-436. doi: 10.1111/j.1365-2605.2012.01280.x.

Langford, K.H., Thomas, K.D., 2008. Inputs of chemicals from recreational activities into the Norwegian coastal zone. Journal of Environmental Monitoring, 10: 894-898.

Li, V.W., Tsui, M.P., Chen, X., Hui, M.N., Jin, L., Lam, R.H., Yu, R.M., Murphy, M.B., Cheng, J., Lam, P.K., Cheng, S.H., 2016. Effects of 4-methylbenzylidene camphor (4MBC) on neuronal and muscular development in zebrafish (Danio rerio) embryos. Environmental Science and Pollution Research, 23(9): 8275-8285. doi: 10.1007/s11356-016-6180-9.

Li, W., Ma, Y., Guo, C., Hu, W., Liu, K., Wang, Y., Zhu, T., 2007. Occurrence and behaviour of four of the most used sunscreen UV filters in a wastewater reclamation plant. Water Research, 41(15): 3506-3512. doi: 10.1016/j.watres.2007.05.039.

Lowe N., 2006. An overview of ultraviolet radiation, sunscreens, and photo-induced dermatoses. Dermatology Clinics, 24(1): 9-17. doi: 10.1016/j.det.2005.08.001. 
Luthe G., Jacobus J.A., Robertson L.W., 2008. Receptor interactions by polybrominated diphenyl ethers versus polychlorinated biphenyls: a theoretical Structure-activity assessment. Environmental Toxicology and Pharmacology, 25(2): 202-210. doi: 10.1016/j.etap.2007.10.017.

Mach M., Grubbs R.D., Price W.A., Paton S.J., Lucot J.B., 2004. Behavioral changes after acetylcholinesterase inhibition with physostigmine in mice. Pharmacology Biochemistry and Behavior, 79(3): 533-540.

Martins, D., Monteiro, M.S., Soares, A.M.V.M., Quintaneiro, C., 2017. Effects of 4-MBC and triclosan in embryos of the frog Pelophylax perezi. Chemosphere 178, 325-332.

McKenzie D.J., 2011. Energy utilisation: the energetics of swimming. In: Farrell A.P., Cech J.J., Richards J.G., Stevens E.D. (Eds.). Encyclopedia of fish physiology, from genome to environment. San Diego, California: Elsevier.

Menon J., Rozman R., 2007. Oxidative stress, tissue remodeling and regression during amphibian metamorphosis. Comparative Biochemistry and Physiology - Part C: Toxicology \& Pharmacology, 145(4): 625-631.

Morais S., Aragão C., Cabrita E., Conceição L.E.C., Constenla, M., Costas B., Dias J., Duncan N., Engrola S., Estevez A., Gisbert E., Mañanós E., Valente L.M.P., Yúfera M., Dinis M.T., 2016. New developments and biological insights into the farming of Solea senegalensis reinforcing its aquaculture potential. Reviews in Aquaculture, 8: 227-263. doi: 10.1111/raq.12091.

Okada N., Tanaka M., Tagawa M., 2003. Bone development during metamorphosis of the Japanese flounder (Paralichthys olivaceus): differential responses to thyroid hormone. In The Big Fish Bang. Proceedings of the 26th Annual Larval Fish Conference (Browman HI and Skiftesvik AB, eds). Bergen: Institute of Marine Research, 11 pp.

Oost R., Beyer J., Vermeulen N.P., 2003. Fish bioaccumulation and biomarkers in environmental risk assessment: a review. Environmental Toxicology and Pharmacology, 13(2): 57-149.

Ozáez I., Martínez-Guitarte J.L., Morcillo G., 2013. Effects of in Vivo Exposure to UV Filters (4-MBC, OMC, BP-3, 4-HB, OC, OD-PABA) on Endocrine Signaling Genes in the Insect Chironomus Riparius. Science of the Total Environment, 456-457:120-6. doi: 10.1016/j.scitotenv.2013.03.081.

Pavlaki M., Araújo M., Cardoso D., Silva A.R., Cruz A., Mendo S., Soares A.MV.M., Calado R., Loureiro S., 2016. Ecotoxicity and genotoxicity of cadmium in different marine trophic levels. Environmental Pollution, 215: 203-212.

Pimentel M., Faleiro F., Diniz M., Machado J., Pousão-Ferreira P., Peck M., Pörtner H., Rosa R., 2015. Oxidative stress and digestive enzyme activity of flatfish larvae in a changing ocean. PLOS One, 10(7): e0134082. 
Power D.M., Einarsdottir I., Pittman K., Sweeney G., Hildahl J., Campinho M.A., Silva N., Saele O., GalayBurgos M., Smaradottir H., Björnsson B.T., 2008. The molecular and endocrine basis of flatfish metamorphosis. Reviews in Fisheries Science, 16 (1): 93-109.

Quintaneiro C., Teixeira B., Benedé J.L., Chisvert A., Soares A.M.V.M., Monteiro M.S., 2019. Toxicity effects of the organic UV-filter 4-Methylbenzylidene camphor in zebrafish embryos. Chemosphere, 218: $273-281$. doi: 10.1016/j.chemosphere.2018.11.096.

Rabasa C., Dickson S.L., 2016. Impact of stress on metabolism and energy balance. Current Opinion in Behavioral Sciences, 6: 71-77. doi: 10.1016/j.cobeha.2016.01.011.

Rao J.V., Begum G., Pallela R., Usman P.K., Rao R.N., 2005. Changes in behavior and brain acetylcholinesterase activity in mosquito fish, Gambusia affinis in response to the sub-lethal exposure to chlorpyrifos. International Journal of Environmental Research and Public Health, 2(3-4): 478-483.

Rudneva I., Kuzminova N., Skuratovskaya E., 2010. Glutathione-S-Transferase Activity in tissues of Black Sea fish species. Asian Journal of Experimental Biological Sciences, 1(1): 141-150.

Sánchez-Rodríguez, A., Sanz, M.R., Betancort, J., 2015. Occurrence of eight UV filters in beaches of Gran Canaria (Canary Islands). An approach to environmental risk assessment. Chemosphere, 131: 85-90.

Sarasquete C., Gisbert E., Ortiz-Delgado J.B., 2019. Embryonic and Larval Ontogeny of the Senegalese Sole, Solea senegalensis: Normal Patterns and Pathological Alterations. In: The Biology of Sole (MuñozCueto J.,A., Sánchez E., L., M., Sánchez-Vázquez F.J., (Eds) CRC Press. 448 pp. ISBN 9781498727839.

Schmutzler C., Gotthardt I., Hofmann P.J., Radovic B., Kovacs G., Stemmler L., Nobis L., Bacinski A., Mentrup B., Ambrugger P., Grüters A., Malendowicz L.K., Christoffel J., Jarry H., Seidlovà-Wuttke D., Wuttke W., Köhrle J. 2007. Endocrine disruptors and the thyroid gland - a combined in vitro and in vivo analysis of potential new biomarkers. Environmental Health Perspectives, 115(Suppl 1): 77-83. doi: 10.1289/ehp.9369.

Scott G.R., Sloman K.A., 2004. The effects of environmental pollutants on complex fish behaviour: integrating behavioural and physiological indicators of toxicity. Aquatic Toxicology, 68(4): 369-392. doi: 10.1016/j.aquatox.2004.03.016.

Sharma M., 2019. Behavioural responses in effect to chemical stress in fish: A review. International Journal of Fisheries and Aquatic Studies 7(1): 01-05.

Shoji J., Toshito S., Mizuno K., Kamimura Y., Hori M., Hirakawa K. 2011. Possible effects of global warming on fish recruitment: shifts in spawning season and latitudinal distribution can alter growth of fish early life stages through changes in day length. ICES Journal of Marine Science, 68: 1165-1169.

Sloman K.A., McNeil P.L., 2012. Using physiology and behavior to understand the responses of fish early life stages to toxicants. Journal of fish biology. 81(7): 2175-98. 
Sowers A.D., Klaine S.J., 2008. The effects of triclosan on the development of Rana palustris. Proceedings of the 2008 South Carolina Water Resources Conference, October 14-15, 2008, USA.

Sun M., Wei F., Li H., Xu J., Chen X., Gong X., Tian Y., Chen S., Bao B., 2015. Distortion of frontal bones results from cell apoptosis by the mechanical force from the up-migrating eye during metamorphosis in Paralichthys olivaceus. Mechanisms of Development, 136: 87-98.

Tata J.R., 1994. Hormonal regulation of programmed cell death during amphibian metamorphosis. Biochemistry and Cell Biology, 72(11-12): 581-588.

Torres J.J., Grigsby M.D., Clarke M.E., 2012. Aerobic and anaerobic metabolism in oxygen minimum layer fishes: the role of alcohol dehydrogenase. Journal of Experimental Biology, 215: 1905-1914. doi: 10.1242/jeb.060236

Torres, T., 2016. Screening the toxicity of selected personal care products using embryo bioassays: 4MBC, propylparaben and triclocarban. International Journal of Molecular Sciences, 17(10): 1762.

Tovar-Sánchez, A., Sánchez-Quiles, D., Basterretxea, G., Benedé, J.L., Chisvert, A., Salvador, A., Moreno, I., Blasco, J., 2013. Sunscreen products as emerging pollutants to coastal waters. PLOS ONE, 8(6): e65451. doi: 10.1371/journal.pone.0065451.

United States Environmental Protection Agency (USEPA), 2012. 40 CFR Part 423 - 126 Priority Pollutants. Appendix A. United States Environmental Protection Agency. Washington, USA.

Vassault A., 1983. Methods of enzymatic analysis. Academic Press, New York, pp. 118-126.

Veldhoen N., Skirrow R.C., Osachoff H., Wigmore H., Clapson D.J., Gunderson M.P., Van Aggelen G., Helbing C.C., 2006. The bactericidal agent triclosan modulates thyroid hormone-associated gene expression and disrupts postembryonic anuran development. Aquatic Toxicology, 80: 217-227.

Vieira L.R., Gravato C., Soares A.M., Morgado F., Guilhermino L., 2009. Acute effects of copper and mercury on the estuarine fish Pomatoschistus microps: linking biomarkers to behaviour. Chemosphere, 76(10): 1416-1427. doi: 10.1016/j.chemosphere.2009.

Wang J., Pan L., Wu S., Lu L., Xu Y., Zhu Y., Guo M., Zhuang S., 2016. Recent advances on endocrine disrupting effects of UV filters. International Journal of Environmental Research and Public Health, 13(8): 782. PMCID: PMC4997468. doi: 10.3390/ijerph13080782.

Wen Y., Schoups G., Giesen N., 2017a. Organic pollution of rivers: Combined threats of urbanization, livestock farming and global climate change. Sci Rep. 7: 43289. PMID: 28230079. doi: 10.1038/srep43289.

Wen B., Jin S.-R., Chen Z.Z., Gao J.-Z., Wang L., Ying L., Liu Y., Liew H.-P., 2017b. Plasticity of energy reserves and metabolic performance of discus fish (Symphysodon aequifasciatus) exposed to low- 
temperature stress. Aquaculture, 481: 169-176. doi: 10.1016/j.aquaculture.2017.09.002.

Yamano K., Miwa S., Obinata T., Inui Y. 1991. Thyroid hormone regulates developmental changes in muscle during flounder metamorphosis. General and Comparative Endocrinology, 81(3): 464-472.

Young A.R. 2006. Acute effects of UVR on human eyes and skin. Progress in Biophysics \& Molecular Biology, 92: 80-85.

Young A.R., Claveau J., Rossi A.B., 2017. Ultraviolet radiation and the skin: Photobiology and sunscreen photoprotection. Journal of the American Academy of Dermatology, 76 (3S1): 100-109.

Yu L., Wan F., Dutta S., Welsh S., Liu Z., Freundt E, Baehrecke E.H., Lenardo M., 2006. Autophagic programmed cell death by selective catalase degradation. Proceedings of the National Academy of Sciences - 28, 103(13): 4952-4957. doi: 10.1073/pnas.0511288103.

Yue Z., Yu M., Zhang X., Dong Y., Tian H., Wang W., Ru S., 2017. Semicarbazide-induced thyroid disruption in Japanese flounder (Paralichthys olivaceus) and its potential mechanisms. Ecotoxicology and Environmental Safety, 140: 131-140. doi: 10.1016/j.ecoenv.2017.02.043.

Yúfera M., Parra G., Santiago R., Carrascosa M., 1999. Growth, carbon, nitrogen and caloric content of Solea senegalensis (Pisces: Soleidae) from egg fertilization to metamorphosis. Marine Biology, 134: 4349.

\section{Tables}

Table 1. Effect concentration (EC), no observed (NOEC) and lowest observed (LOEC) effect concentration of 4-MBC during metamorphosis of Solea senegalensis. Exposure to 4-MBC was performed at 13 days after hatching (dah) during 48h. Endpoints were analysed during and/or at the end of exposure (14 and 15 dah) and during maintenance in clean medium until complete metamorphosis (24 dah).

Concentrations under square brackets express the $95 \%$ confidence interval of the three parameter logistic regression. CAT - catalase, LPO - lipid peroxidation. 


\begin{tabular}{|llll|}
\hline Endpoint & $\mathrm{EC}_{20}$ & $\begin{array}{l}\text { NOEC } \\
\left(\mathrm{mg} \mathrm{L}^{-1}\right)\end{array}$ & $\begin{array}{l}\text { LOEC } \\
\left(\mathrm{mg} \mathrm{L}^{-1}\right)\end{array}$ \\
\hline Mortality & & & \\
14 dah & & - & - \\
15 dah & $1.606[1.389-1.886]$ & - & - \\
24 dah & $1.547[1.373-1.923]$ & - & - \\
\hline Malformations & $1.442[1.234-1.816]$ & - & - \\
14 dah & & & - \\
15 dah & $0.883[0.617-1.219]$ & - & 0.200 \\
\hline Metamorphosis progression (14, 17 dah) & - & - & 0.928 \\
\hline Growth (24 dah) & - & - & $0.644[0.750-1.399]$ \\
\hline Biochemical markers - CAT, LPO (24 dah) & - & 0.632 & 0.928 \\
\hline
\end{tabular}

\section{Figures}




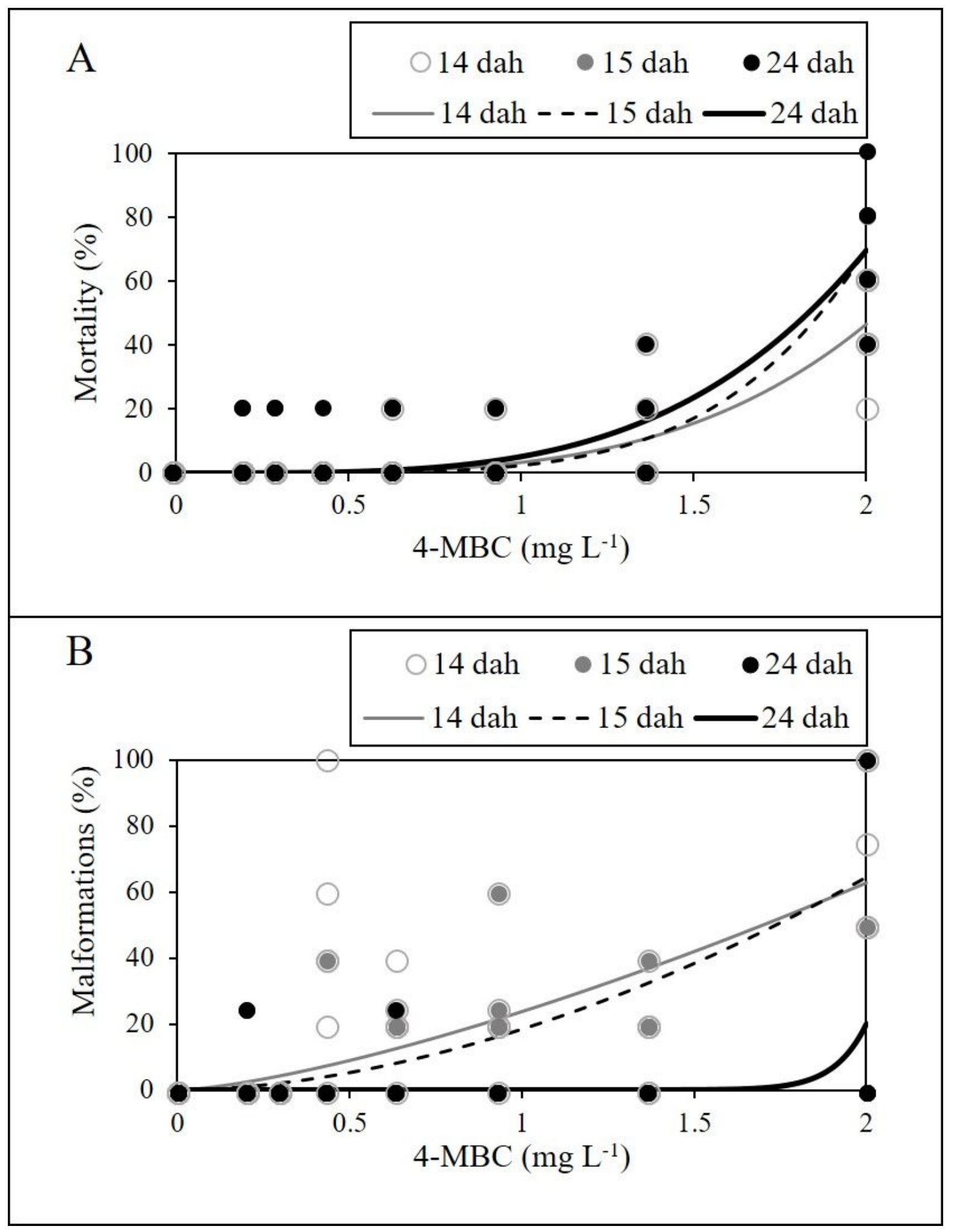

\section{Figure 1}

Mortality (A) and malformations (B) of metamorphosing Solea senegalensis after $48 \mathrm{~h}$ exposure to 4MBC. Exposure was performed at 13 days after hatching (dah) during $48 \mathrm{~h}$ and fish maintained in clean medium until complete metamorphosis, at 24 dah. Dots represent mortality and malformations of S. senegalensis at each age ( $n=6,5$ fish per replicate). Parameters of the logistic regressions are available in supplementary table S3. 

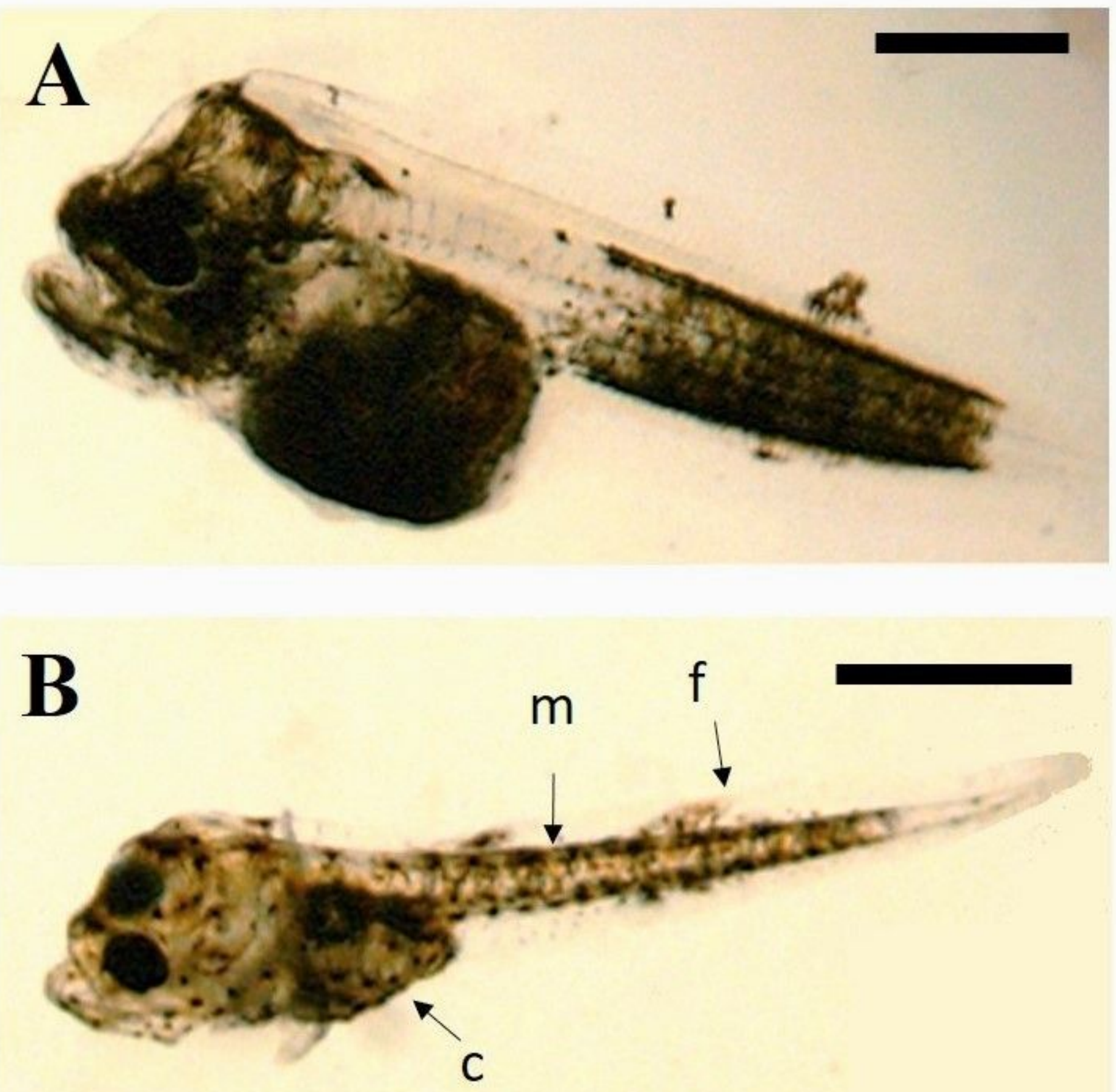

\section{Figure 2}

Malformations in metamorphosing Solea senegalensis after 48h exposure to 4-MBC. Exposure was performed at 13 days after hatching (dah) during 48h and fish maintained in clean medium until complete metamorphosis, at 24 dah. Fish showed alterations on skin pigmentation, abdominal cavity, fins and pigmentation. A - negative control fish; B - fish exposed to $1.363 \mathrm{mg} \mathrm{L-1}$ of 4-MBC with simultaneous alteration of pigmentation $(\mathrm{m})$, abdominal cavity (c), fins (f) and altered pigmentation. Black bar represents $1 \mathrm{~mm}$. 


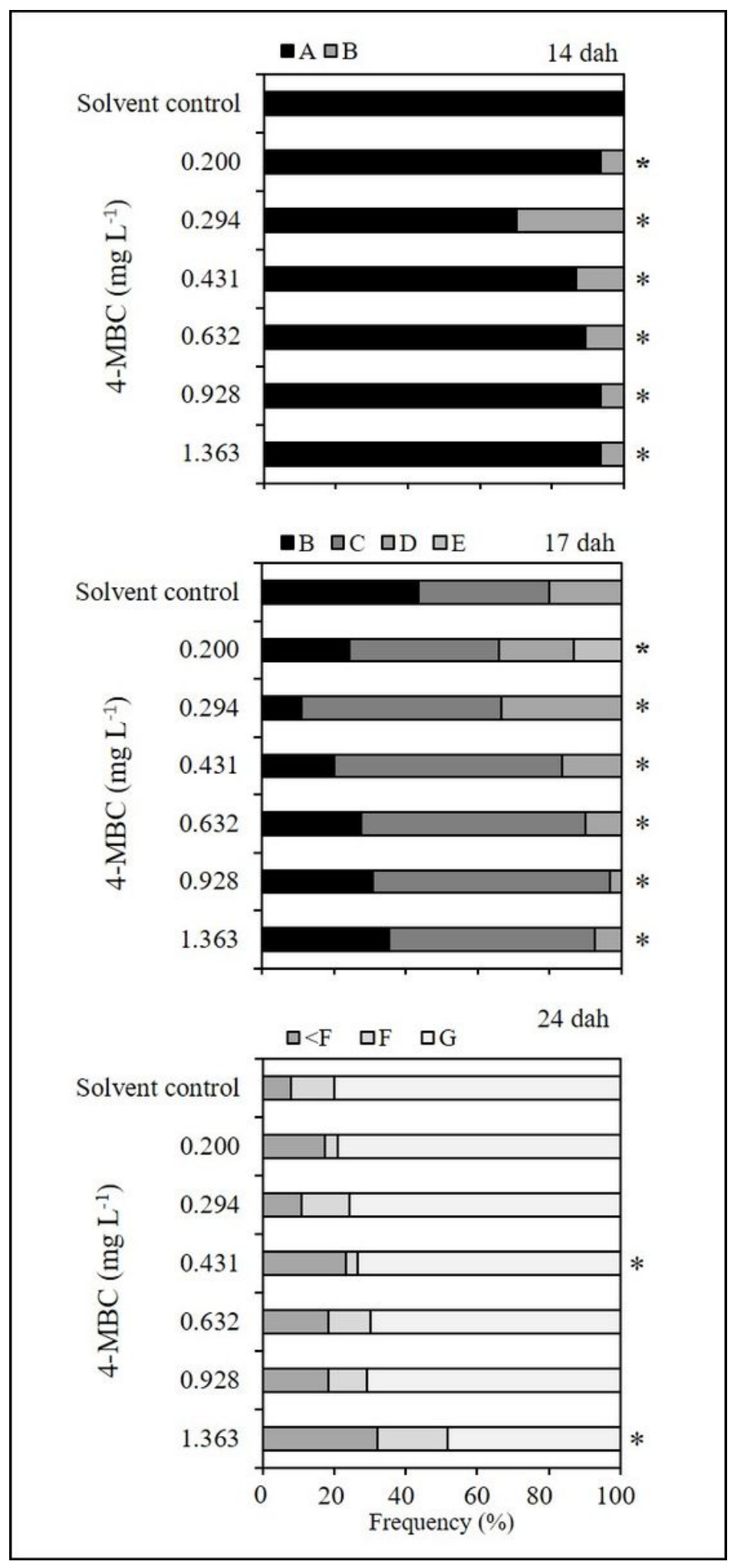

\section{Figure 3}

Metamorphosis progression of Solea senegalensis after 48h exposure to 4-MBC. Exposure was performed at 13 days after hatching (dah) during $48 \mathrm{~h}$ and then fish were maintained in clean medium until complete metamorphosis, at 24 dah. Data represent the percentage of fish in each development stage in each treatment group. A - Beginning of enlargement and pigmentation of dorsal and ventral fins, $B$ - Beginning of migration of left eye to the right side Further pigmentation of fins, C - Further migration of 
left eye and pigmentation, Alteration of mouth shape, D - Further migration of left eye and pigmentation, Fully enlargement of dorsal and ventral fins, Further alteration of mouth shape, E - Fully flattened body, Left eye on the dorsal side, F - Further migration of left eye on the dorsal side, G - Growth of anal fin, Shrink of pectoral fin, Orbital arch becomes clearly visible. * represent significant differences between fish in 4-MBC exposure group and solvent control fish group at each day ( $<<0.05$, Chi-square test).

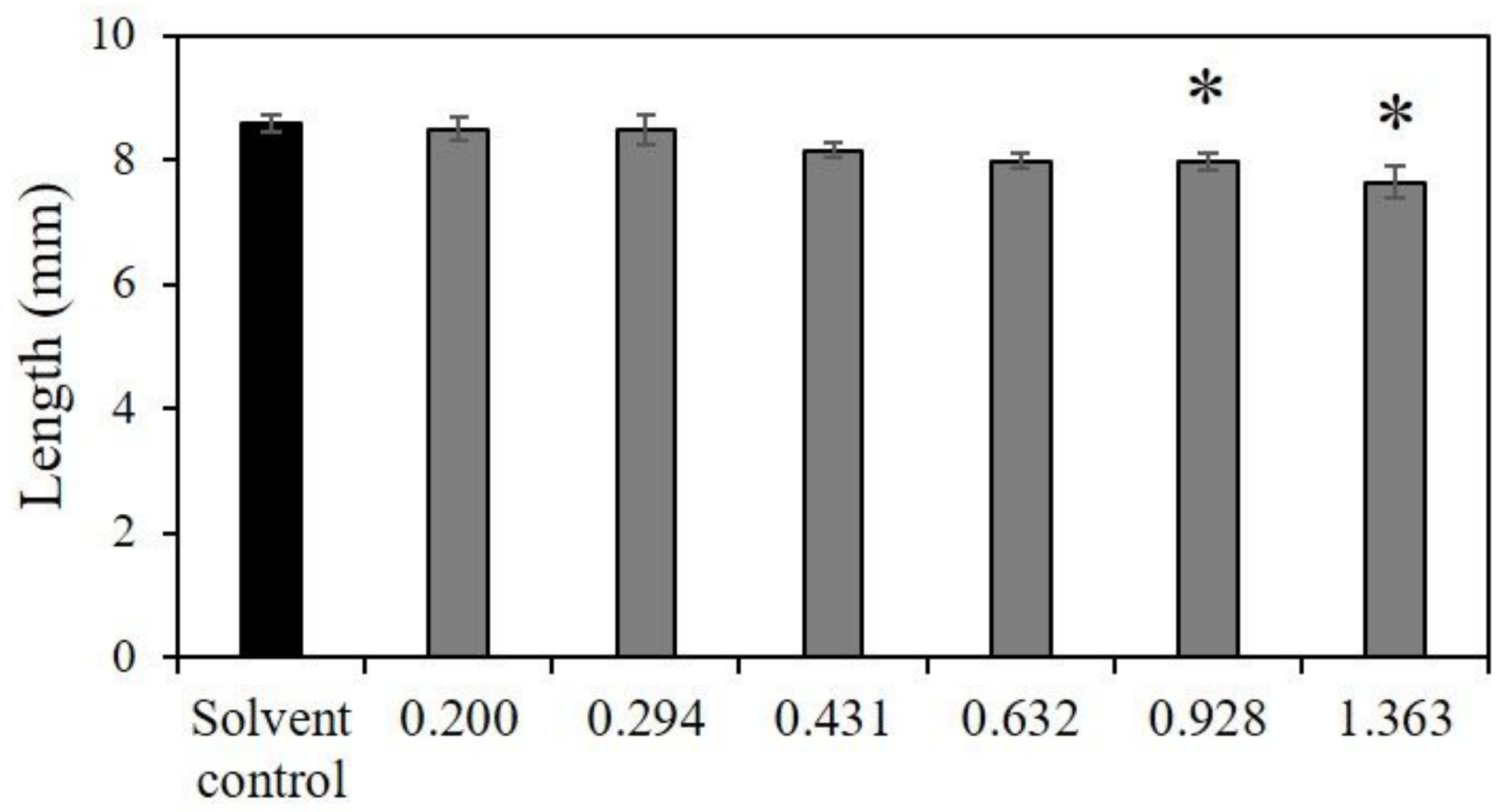

\section{4-MBC (mg l-1)}

Figure 4

Length of Solea senegalensis at the end of metamorphosis, at 24 days after hatching (dah).. Exposure to 4-MBC was performed at 13 dah during $48 \mathrm{~h}$ and fish maintained in clean medium until complete metamorphosis, at 24 dah.* represent significant differences from solvent control $(p<0.05$, One-way ANOVA followed by Pairwise Dunnett's test). 


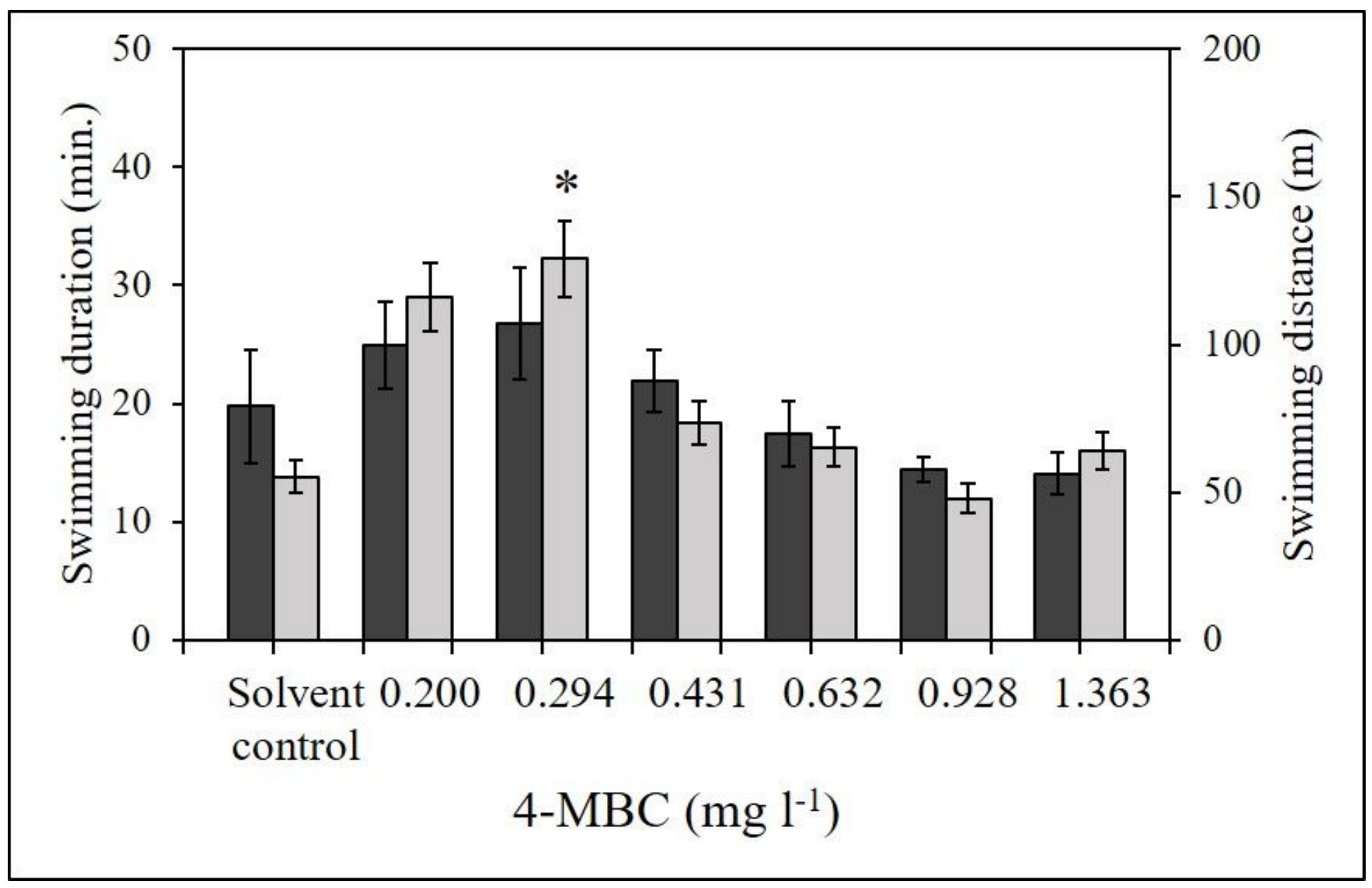

Figure 5

Swimming duration (black bar) and swimming distance (grey bar) of Solea senegalensis at the 60 min behavior test performed at the end of metamorphosis (24 days after hatching, dah). Exposure to 4-MBC was performed at 13 dah during $48 \mathrm{~h}$ and fish maintained in clean medium until complete metamorphosis, at 24 dah. * represent significant differences from solvent control group $(p<0.05$, Oneway ANOVA followed by Pairwise Dunnett's test). 

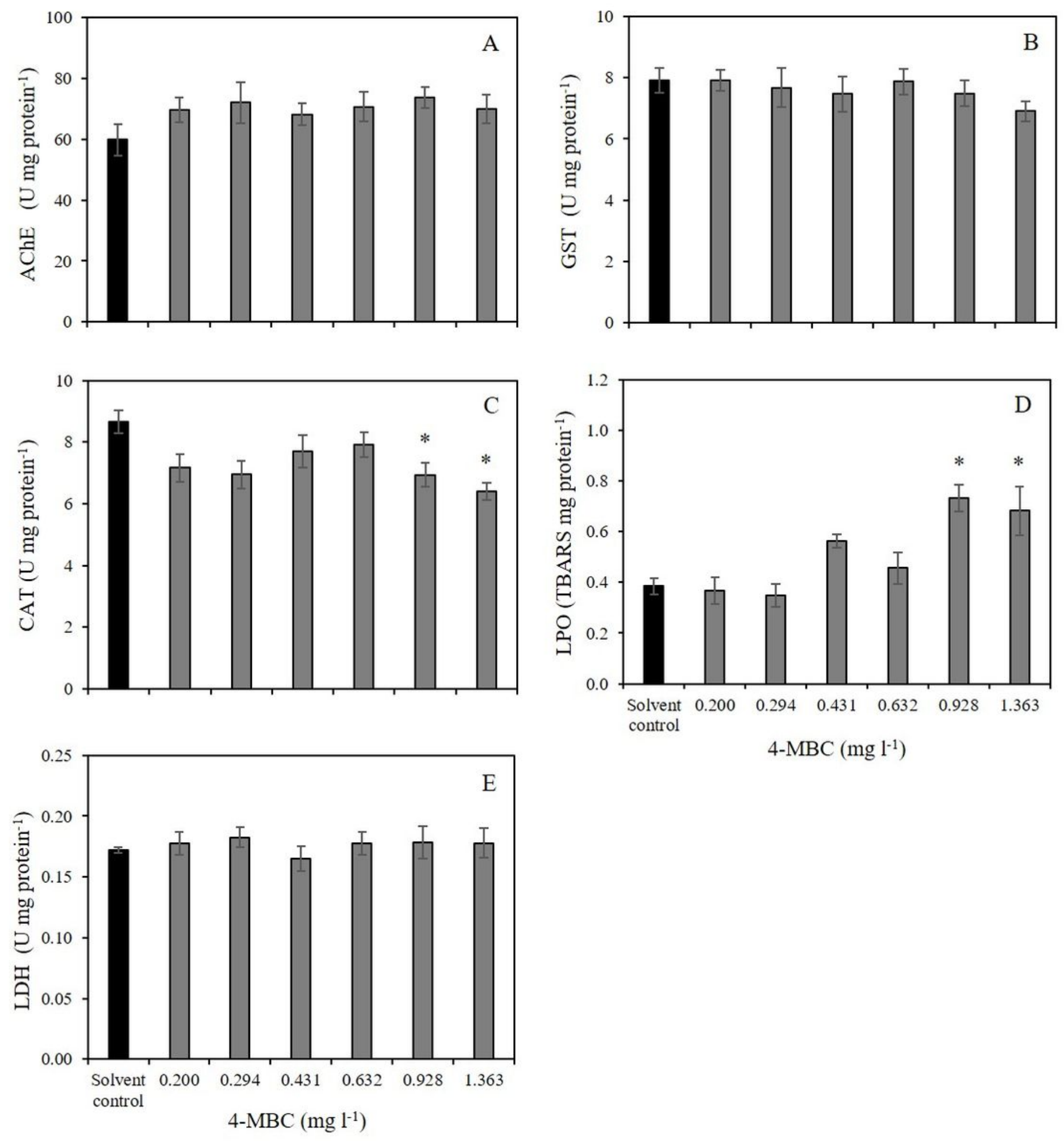

4-MBC (mg l-1)

\section{Figure 6}

Biochemical responses of Solea senegalensis at the end of metamorphosis (24 days after hatching, dah) after 48h exposure to 4-MBC at 13 dah. A - Acetilcholinesterase (AChE) activity, B - Glutathione S-

Transferase (GST) activity, C - Catalase (CAT) activity, D - Lipid peroxidation (LPO) levels and E - Lactate dehydrogenase (LDH) activity. * represent the existence of significant differences with respective solvent control ( $p<0.05$, One-way ANOVA followed by Pairwise Dunnett's test). 


\section{Supplementary Files}

This is a list of supplementary files associated with this preprint. Click to download.

- CaptionSupFig..docx

- Fig.S1.jpg

- Fig.S2.jpg

- Sup.tables.docx

- graphicalabst.jpg 